Issued by Sandia National Laboratories, operated for the United States Department of Energy by Sandia Corporation.

NOTICE: This report was prepared as an account of work sponsored by an agency of the United States Government. Neither the United States Government nor any agency thereof, nor any of their employees, nor any of their contractors, subcontractors, or their employees, makes any warranty, express or implied, or assumes any legal liability or responsibility for the accuracy, completeness, or usefulness of any information, apparatus, product, or process disclosed, or represents that its use would not infringe privately owned rights. Reference herein to any specific commercial product, process, or service by trade name, trademark, manufacturer, or otherwise, does not necessarily constitute or imply its endorsement, recommendation, or favoring by the United States Government, any agency thereof or any of their contractors or subcontractors. The views and opinions expressed herein do not necessarily state or reflect those of the United States Government, any agency thereof or any of their contractors.

Printed in the United States of America. This report has been reproduced directly from the best available copy.

Available to DOE and DOE contractors from

Office of Scientific and Technical Information

PO Box 62

Oak Ridge, TN 37831

Prices available from (615) 576-8401, FTS 626-8401

Available to the public from

National Technical Information Service

US Department of Commerce

5285 Port Royal RD

Springfield, VA 22161

NTIS price codes

Printed copy: A02

Microfiche copy: A06 


\section{DISCLAIMER}

Portions of this document may be illegible in electronic image products. Images are produced from the best available original document. 
Distribution

Category UC-705

SAND 94-1327

Unlimited Release

Printed August 1994

\title{
Sandia National Laboratories Embraces ISDN
}

L. F. Tolendino, Department 13916 and J. M. Eldridge, Department 13917

Sandia National Laboratories

Albuquerque, New Mexico

\begin{abstract}
Sandia National Laboratories (Sandia), a multidisciplinary research and development laboratory located on Kirtland Air Force Base, has embraced Integrated Services Digital Network technology as an integral part of its communication network. Sandia and the Department of Energy's Albuquerque Operations Office have recently completed the installation of a modernized and expanded telephone system based on the AT\&T 5ESS telephone switch.

Sandia is committed to ISDN as an integral part of data communication services, and it views ISDN as one part of a continuum of services -- services that range from ISDN's asynchronous and limited bandwidth Ethernet (250-1000 Kbps) through full bandwidth Ethernet, FDDI, and ATM at Sonet rates. Sandia has demonstrated this commitment through its use of ISDN data features to support critical programmatic services such as access to corporate data base systems. In the future, ISDN will provide enhanced voice, data communication, and video services.
\end{abstract}

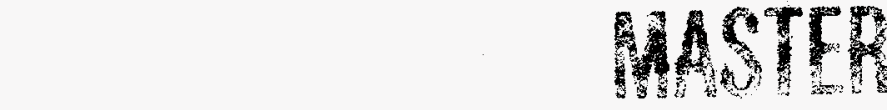




\section{Introduction}

Sandia National Laboratories is a multidisciplinary research and development laboratory with major facilities in Albuquerque, New Mexico and Livermore, California. The laboratory employs approximately 8,500 full time workers in a campus like environment that encompasses several Technical Areas at both locations. The work environment is very computing and communications intensive with state of the art resources such as Massivly Parallel Processors, Super Computers, hundreds of engineering work stations and thousands of personal computers. Within this environment Sandia provides all communication services including telephone and high speed data. The following system description describes the system as it is installed at the New Mexico site and references to Sandia below refer to the New Mexico site. However, except for size the systems in New Mexico and California are essentially identical.

\section{System Description}

Sandia National Laboratories has embraced ISDN, Integrated Services Digital Network, technology as an integral part of the communications network. Sandia and the Albuquerque Operations Office of the Department of Energy have recently completed the installation of a modernized and expanded AT\&T 5ESS based telephone network. The $5 E S S$, running the latest generic software available, provides universal digital voice and data services to over 12,500 Department of Energy and Sandia customers. As currently configured, the 5ESS system consists of a base unit and two Optical Remote Modules, ORMs (see Figure 1). Other major system components consist of two Application Processors that support the AT\&T Advanced Communications Package (ACP) and a voice mail system. The ACP software package provides electronic directory services, message detail recording, calling number identification, as well as other features.

While the 5ESS currently serves all customers, Sandia will install a third ORM to provide universal digital services. The system is currently equipped with a total of 18,000 lines of which 7,000 are ISDN. Sandia's second 5ESS telephone switch in California has about 1,700 total lines, and two Primary Rate Interface circuits interconnect the two 5ESS switches.

Sandia is committed to ISDN as an integral part of our data communication services and views ISDN as one part of a continuum of services that range from ISDN to Ethernet and FDDI networks and to ATM and SONET telecommunications. ISDN gives our customers an entry into that continuum of services by providing them with bandwidth on demand where and when they need it.

Our use of ISDN data communications to support critical programmatic services such as access to corporate data base systems demonstrates our commitment to ISDN. Sandia has assumed the burden of supporting these services in house and has developed a data base management system for telecommunications services. The database system plays and an integral role in Sandia's telephone and data provisioning. We perform all work orders, work assignments, and documentation assignments through the database system. This 
support commitment has been critical to Sandia's successful installation of ISDN since the database technology for managing a telephone system for several thousand ISDN customers is not commercially available.

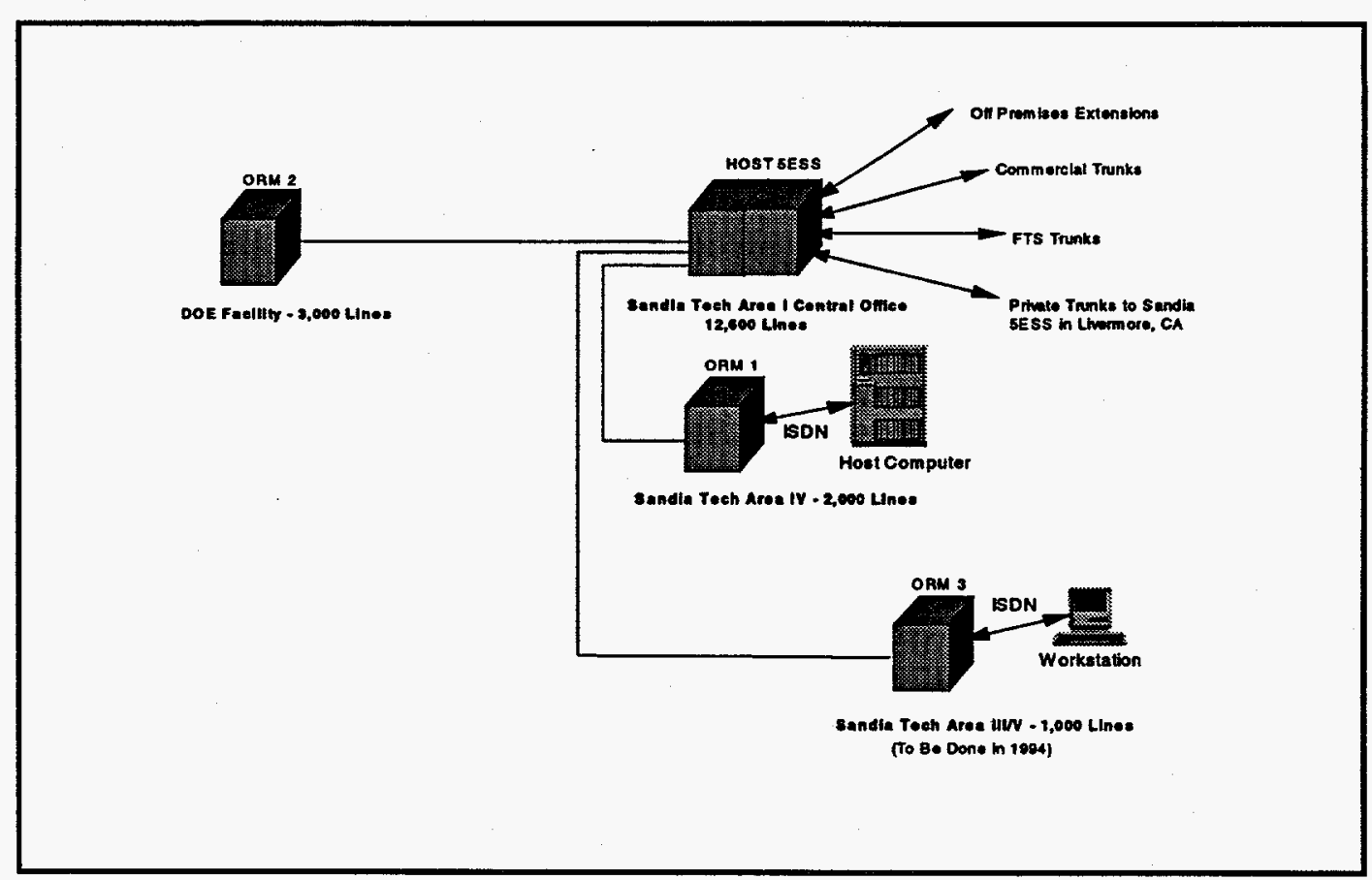

\section{Figure 1- 5ESS Switch Configuration}

The 5ESS system is capable of supporting about 7,000 ISDN stations as it is currently configured and stations are being installed at a rate of 200 per week. Currently the system has over 4300 stations installed that are now mainly used for their advanced voice and data features. However, as a first data offering, we installed over 1,600 ISDN lines for asynchronous data service as of May 1, 1994. We have also installed several hundred computer or host drops. Even though many of the these customers are familiar with the use of data communications, we have found that it is necessary to provide them with ISDN specific training.

\section{ISDN Voice Features}

When installing telephone service, Sandia has taken the approach of enabling as many voice features as possible regardless of whether or not the customer specifically needs all of those features. We have developed standardized feature packages that we use on all ISDN telephones. We have built each package from a fixed set of voice features and tailored it to the capabilities of the particular ISDN phone model. By enabling rich feature sets and minimizing the number of different configurations, we have reduced the amount of administrative and maintenance effort needed to operate the telephone system. Customers also benefit from the availability of a wide range of voice features and a consistent telephone environment throughout the system. We currently support two levels of ISDN service -- basic and advanced, or secretarial. Advanced service uses more 
expensive ISDN telephones that have greater flexibility for one button feature programming. It primarily has all of the voice features of the basic service plus the capability to handle call coverage service.

The first services apparent to a new customer are the ISDN voice features. Immediately the customer is aware of caller ID for all on-switch calls and the presence of the message waiting indicator for voice mail. Caller ID is currently available on all 4,300 ISDN stations, and the Auxiliary Processor systems process approximately 15,000 Caller ID requests in a typical 24 hour period. Next the customers become aware of the Electronic Directory Service, EDS, that allows them to place a phone call by dialing the other parties name rather than phone number. An automatic program downloads data from the DOE and Sandia corporate databases every week to update the EDS data on the AP system. The EDS system has rapidly become the most visible feature on the new ISDN stations since it provides customers more accurate phone number information than is possible with printed phone books. Customers place approximately 1,000 directory queries a day.

In addition to providing new services, ISDN stations also make it easier for the customer to use features such as 3-way or 6-way conferencing, call transfer, and call forwarding. With the new ISDN stations, a single push of a programmable feature button replaces hard to remember feature codes, thus making telephone use more convenient. As currently configured, all ISDN stations have three the primary telephone number appearances. Two call appearance buttons can accept and initiate both incoming and outgoing calls while the third can only initiate outgoing calls. This allows the customer to efficiently handle multiple calls without the need for multiple lines or special call hold equipment.

ISDN voice features such as multiple call appearances and caller-ID have allowed Sandia to replace each of the various style key systems present on site with a single, common

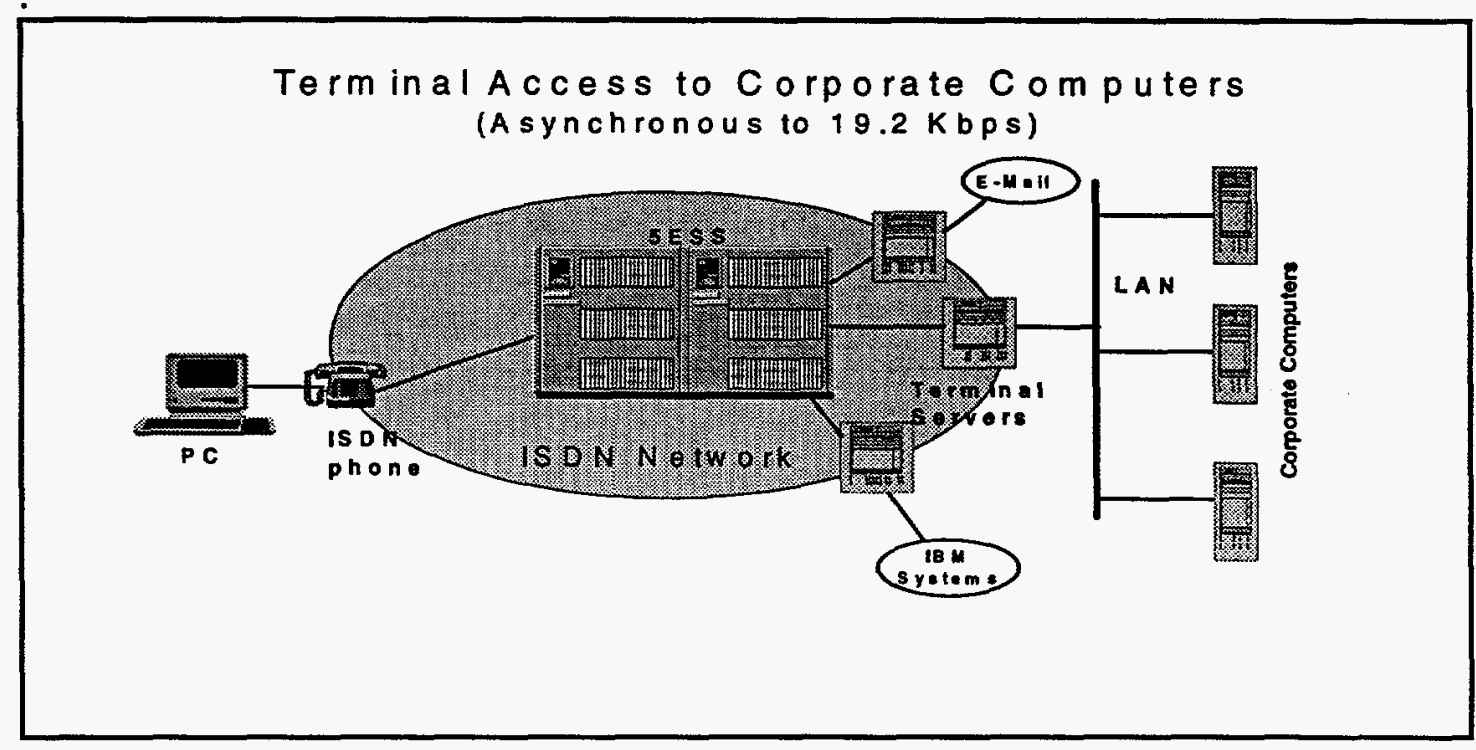

Figure 2 - ISDN Terminal Communication 
ISDN secretarial station that uses fewer cable pairs within the building. ISDN stations provide call coverage services that are far superior to those provided by the key systems they replace, and they provide those services at far less cost and with better reliability. This replacement has allowed standardization that has improved operational efficiency while utilizing the installed single pair wire plant. Gone are the days requiring bulky 25 pair cables for $1 \mathrm{~A} 2$ key systems or multi-line stations. Indeed, the ability to use the installed cable plant of one pair of wires to each desk, was critical to the decision to upgrade to a digital ISDN based system. Other PBX type systems considered required at least two cable pair to each desk to provide digital services.

\section{ISDN Data Services}

ISDN provides a core data utility for Sandia; all of our ISDN phones have a built-in data module capable of data transmission at rates up to $64 \mathrm{Kbps}$. The idea is to provide a base level of data communications to all customers. The first data services installed extensively are ISDN asynchronous data services. These services provide an asynchronous data link between the customer's data device connected to the ISDN station via an RS232 connector to other asynchronous data devices connected to the 5ESS system. Typical data devices are personal computers, computer terminals and host computer ports. The most common use of this service is to connect a PC to a centralized corporate host computer as shown in figure 2.

Asynchronous data service to these central site computers utilizes the ISDN packet switching on the $\mathrm{D}$ channel. This channel is capable of supporting up to $19.2 \mathrm{Kbps}$ asynchronous data streams. The telephone instrument encapsulates data into X.25 packets to be switched in the 5ESS architecture. This asynchronous data service has proved invaluable as a path to E-mail systems and other corporate resources for customers that do not have direct access to a local area network. While customer devices perform packet switching on the Basic Rate Interface, BRI, D channel, host computer ports perform packet switching on the BRI's B channel(s). Use of the switch's X.25 packet service for access to centralized corporate computers has several benefits. First it provides reasonable bandwidth for this application without putting a heavy resource burden on the switch. Packet switched data calls do not compete with voice calls for switch time slots; thus, the switch is smaller and less expensive than it might be otherwise. Second, X.25 allows us to multiplex many customer calls over a single BRI at the central computer. Hence, we need fewer cable pairs and circuits for the host ports. The X.25 packet assemblers/disassemblers we use allow us to multiplex up to 30 asynchronous host computer ports over one BRI. Sandia has approximately 500 computer ports serving 30 centralized host computers available through the 5ESS system.

Since all ISDN stations at Sandia have a built-in data module, PC-to-PC communication and $\mathrm{PC}$ control of the phone's voice and data features are possible. A number of applications at Sandia use this capability. When customers initiate PC-to-PC communication, that may involve much data transfer, they have the option of using circuit switching over the BRI B channel. This communication mode operates at $64 \mathrm{Kbps}$ which is substantially faster and more reliable than standard analog modems. Customers can dial 
each other's PC and set up file transfers using popular protocols such as Kermit or XModem. Such connections require cooperation between the customers but are far superior to "sneaker net," the copying of files to floppy disk and transporting the floppy to the destination PC.

Various communication software packages can utilize the ISDN asynchronous service since the station can emulate the popular Hayes modem command set. This means that not only can terminal emulation software use the ISDN communications port, but also Personal Information Management, PIM, software can use it as well. Such software includes electronic address book software such as the "Cardfile" application included with Microsoft Windows and productivity packages for "electronic white-board" communication. A PC that is connected to the ISDN telephone can control the voice and data operations of the phone. One customer benefit is the ability to have an electronic address book on the customer's PC, where the customer can perform a name search and automatically dial a voice call from the PC. This is an efficient way of keeping track of infrequently used numbers and executing calls. PC software is available to monitor incoming phone calls and screen out those that the customer may not wish to immediately answer. Other software packages are able to recall database information based on the calling parties phone number. These software applications are useful for trouble and help desks.

\section{Ethernet Interconnection}

Ethernet bridges that have a built-in BRI interface can make use of 5ESS switch bandwidth. Such connections allow us to bridge widely separated Ethernet segments as

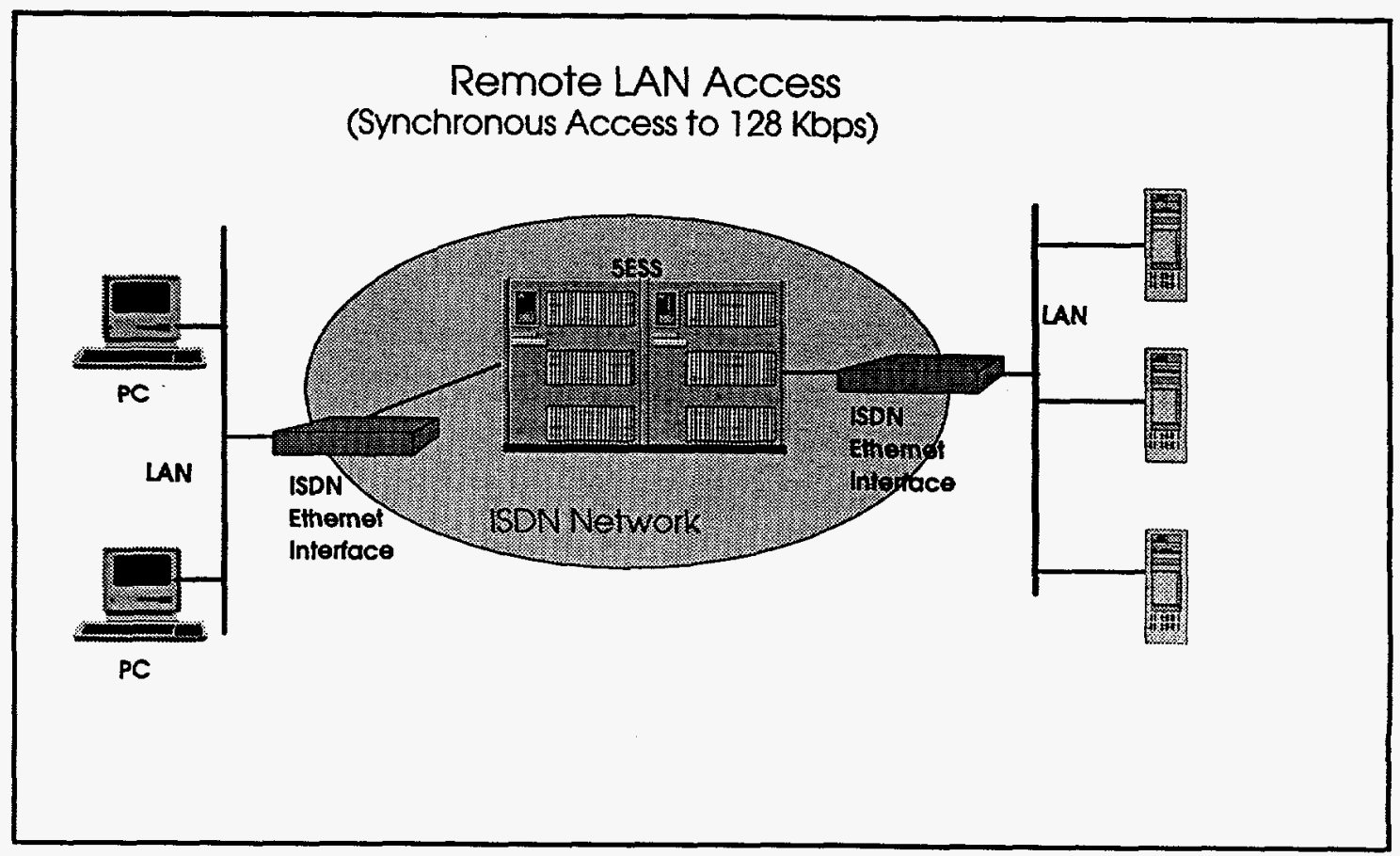

Figure 3 - Ethernet Bridging Via an ISDN Basic Rate Interface Line 
shown in Figure 3. Alternately, the ISDN to Ethernet connection can provide a "Dial-ALAN" service capable of connecting a remote work-station to a LAN. We have tested several ISDN-to-Ethernet devices and the results are encouraging. The devices can use either one or both of the BRI's B channels to provide a bandwidth of $128 \mathrm{Kbps}$. Using the bridge's built-in data compression hardware, we have measured average data transfer rates of $250 \mathrm{Kbps}$ and peak data transfer rates of about $500 \mathrm{Kbps}$.

\section{Video Teleconferencing}

Video teleconferencing that utilizes the ISDN services of the 5ESS is another application that we will soon put into production. Using the BRI B channels, customers can set up a video teleconferences on an as needed basis. Figure 4 shows a typical implementation. Such implementations require the use of one or more dedicated BRI lines; therefore, normal telephone service could not be supported simultaneously with a video teleconference.

\section{Work From Home}

Sandia is very interested in using ISDN services for remote tele-commuting. A number of employees have job responsibilities that make it desirable for them to have communication access form their homes to computers and networks located at Sandia. Some of these responsibilities include out-of-hours network monitoring and trouble shooting, and remote initiation, control, and monitoring of large computer codes. Other employees have found that they can make more efficient use of their time by working at home for part of the work week. A shortage of office space at Sandia's main location has caused Sandia to lease office space in several office buildings around the city of Albuquerque for employees. When employees move to these off-site buildings, they require voice and data communications similar to what is available to those employees on-site. We expect that

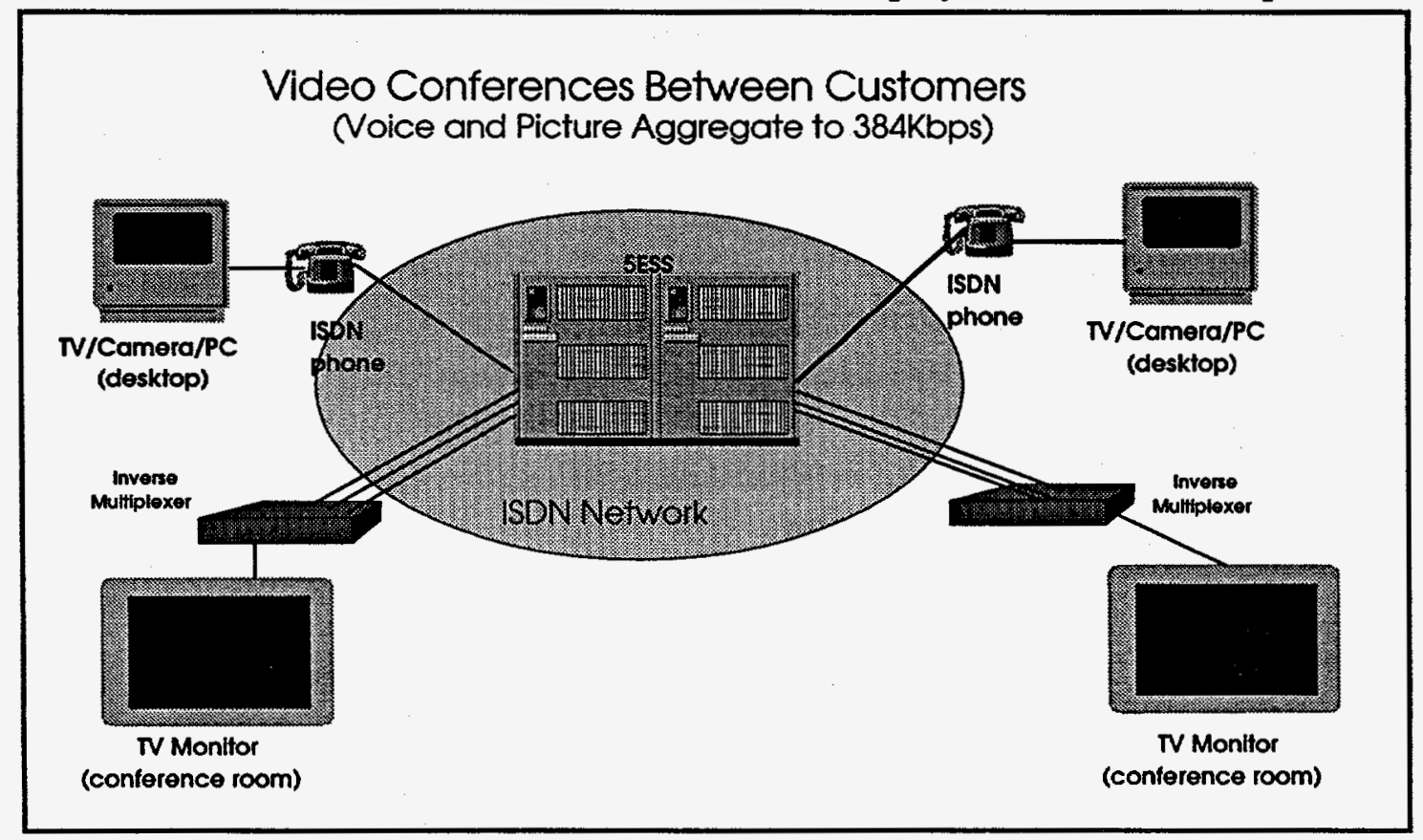

Figure 4 - Personal and Group Video Conferencing 
ISDN will play a key role in providing these employees with communication services.

A dialog is under way with the local exchange carrier, US West, to provide ISDN services to the home. We are planning a trail installation of about 40 ISDN circuits to the home in late 1994; however, US West will paced the trial while they complete service provisioning. Additionally, we are working with US West to install about 400 ISDN circuits for employees located at off-site office buildings.

\section{Summary}

Sandia views ISDN as a key component of our communications services and will continue to exploit this capability at every opportunity. ISDN is an evolving technology which will soon merge with ATM, Asynchronous Transfer Mode, switching technology to provide Broadband ISDN telecommunication service to our customers. 
Copy to:

MS9037 R. J. Detry, 8200

MS9003 D. L. Crawford, 8900

MS 9040 G. Gutierrez, 8902

MS9011 P. W. Dean, 8910

MS9011 Y. S. Yu, 8910

MS1375 L. D. Bertholf, 12400

MS0630 M. J. Eaton, 13100

MS0630 P. D. Merillat, 13110

MS0803 J. F. Jones, 13200

MS0629 M. G. Robles, 13300

MS0630 L. H. Pitts, 13400

MS0809 G. C. Shepherd, 13411

MS0801 M. J. Murphy, 13900

MS0806 R. C. Dougherty, 13902

MS0806 D. C. Jones, 13903

MS0813 D. S. Rarick, 13911

MS0809 G. E. Connor, 13912

MS1090 L. B. Cox, 13912

MS0809 M. R. Heiser, 13912

MS1090 D. A. Paulsen, 13912

MS0809 M. E. Mefford, 13913

MS0806 T. Archuleta, 13913

MS0809 D. P. Duggan, 13913

MS0805 J. P. Sena, 13914

MS0805 P. P. Baca, 13914

MS0805 Natalie Lopez, 13914

MS0805 K. Montano, 13914

MS0805 P. J. Montavon, 13914

MS0805 Lupe Montoya, 13914

MS0807 M. O. Vahle, 13916

MS0807 J. P.Brenkosh, 13916

MS0807 S. A. Gossage, 13916

MS0807 J. H. Maestas, 13916

MS0807 L. Martinez, 13916

MS0807 J. H. Naegle, 13916

MS0807 L. G. Pierson, 13916

MS0807 T. J. Pratt, 13916

MS0807 N. Testi, 13916

MS0807 L. F. Tolendino, 13916 (10)

MS0807 E. L. Witzke, 13916

MS0807 I. C. Alexander, 13917

MS0807 R. L. Adams, 13917
MS0807 A. Breckinridge, 13917

MS0807 J. M. Eldridge, 13917 (10)

MS0807 T. C. Hu, 13917

MS0807 M. M. Miller, 13917

MS0807 S. D. Nelson, 13917

MS0807 M. A. Schaefer, 13917

MS0807 B. Whittet, 13917

MS0806 R. M. Cahoon, 13918

MS0806 W. L. Larson, 13918

MS0806 J. P. Long, 13918

MS0806 R. A. Haynes, 13918

MS0811 R. J. Pryor, 13919

MS0811 T. R. Frytz, 13919

MS0811 G. D Machin, 13919

MS0811 C. D. Brown, 13921

MS0811 R. G. Hawkins, 13921

MS0811 D. J. Ortiz, 13921

MS0811 W. H. Rahe, 13921

MS0811 P. D. Sands, 13921

Ralph Hinshaw, DOE/AL-IMD

Mike Gomez, DOE/AL-IMD

MS0899 Technical Library, 13414 (7)

MS00619 Technical Publications, 13416

MS1119 Document Processing for DOE/OSTI, 7613-2 (10)

MS9017 Central Technical Files, 8523-2 